\title{
A NOTE ON THE SCHOLZ-BRAUER PROBLEM IN ADDITION CHAINS
}

W. R. UTZ

1. Introduction. An addition chain for the positive integer $\boldsymbol{n}$ is a sequence of integers $a_{0}=1<a_{1}<a_{2}<\cdots<a_{r}=n$ where, for each $i>0, a_{i}=a_{j}+a_{k}$, for some $j, k>i$ ( $j=k$ is permitted). For example, $1,2,4,8,10 ; 1,2,3,6,9,10 ; 1,2,4,6,10$ are three addition chains for $n=10$. By $l(n)$ one means the smallest $r$ for which there is an addition chain for $n$. One can easily verify that $l(1)=0, l(2)=1$, $l(3)=l(4)=2, l(5)=l(6)=l(8)=3, l(7)=l(9)=l(10)=l(12)=l(16)=4$ and that $l\left(2^{n}\right)=n$.

A. Scholz [2] published the following as problems:

$$
\begin{aligned}
m+1 \leqq l(n) & \leqq 2 m \text { for } 2^{m}+1 \leqq n \leqq 2^{m+1}, \quad m \geqq 1, \\
l(a b) & \leqq l(a)+l(b), \\
l\left(2^{q}-1\right) & \leqq q+l(q)-1 .
\end{aligned}
$$

A. T. Brauer [1] established (1) and (2) and also improved another inequality suggested by Scholz. When considering (3) Brauer showed that (3) holds if the chains admitted in determining $l(q)$ are restricted. So far as the author can discover, the original problem (3) of Scholz has not been solved. In this note we establish (3) for some values of $q$ by a method that may extend to an arbitrary $q$.

2. The case $q=2^{*}\left(2^{n}+1\right)$.

LEMмA 1. $l(2 *+1)=s+1, s \geqq 0$.

Proof. Clearly, $l\left(2^{*}+1\right) \leqq s+1$ since

$$
1,2,2^{2}, 2^{8}, \cdots, 2^{\bullet}, 2^{\bullet}+1
$$

is an addition chain for $2^{8}+1$. Also,

$$
2^{s}-1<2^{s}+1<2^{s+1}
$$

hence, by (1), $l\left(2^{*}+1\right) \geqq s+1$ and the lemma is proved.

LEMMA 2. $l\left(2^{q}-1\right) \leqq q+l(q)-1=2^{s}+s-1$ if $q=2^{s}, s \geqq 0$.

Proof. This is shown by induction. The inequality holds for $s=0$; suppose it holds for $s=r-1$. Then setting $m=2^{r-1}$,

Presented to the Society, April 24, 1953; received by the editors October 16, 1952. 


$$
\begin{aligned}
l\left(2^{2 m}-1\right) & =l\left[\left(2^{m}-1\right)\left(2^{m}+1\right)\right] \leqq l\left(2^{m}-1\right)+l\left(2^{m}+1\right) \\
& \leqq 2^{r}+r-1
\end{aligned}
$$

by Lemma 1 and the induction hypothesis. This completes the proof.

LEMMA 3. $l\left(2^{q+1}-1\right) \leqq q+l(q+1)=2^{s}+s+1$ if $q=2^{s}, s \geqq 0$.

PROOF. $l\left(2^{a+1}-1\right) \leqq l\left(2^{a+1}-2\right)+1 \leqq l(2)+l\left(2^{a}-1\right)+1 \leqq 2^{a}+s+1$ by Lemma 2.

LEMMA 4. $l\left(2^{*}\left(2^{n}+1\right)\right)=n+s+1, s, n \geqq 0$.

ProOF. (a) $2^{n+s}-1<2^{s}\left(2^{n}+1\right)<2^{n+s+1}$ hence $l\left(2^{*}\left(2^{n}+1\right)\right) \geqq n+s+1$ by (1).

(b) $l\left(2^{\bullet}\left(2^{n}+1\right)\right) \leqq l\left(2^{a}\right)+l\left(2^{n}+1\right)=n+s+1$ by Lemma 1 and property (2).

TheOREM 1. $l\left(2^{q}-1\right) \leqq q+l(q)-1=2^{*}\left(2^{n}+1\right)+n+s$ if $q=2^{s}\left(2^{n}+1\right)$, $s, n \geqq 0$.

Proof. This proof will be by induction on $s$. We have seen in Lemma 3 that the theorem is true if $s=0$. Assume, for the induction proof, that it holds for $s=r-1$ and all $n \geqq 0$. If $m=2^{r-1}\left(2^{n}+1\right)$,

$$
\begin{aligned}
l\left(2^{2 m}-1\right) & \leqq l\left[\left(2^{m}-1\right)\left(2^{m}+1\right)\right] \\
& \leqq 2^{-1}\left(2^{n}+1\right)+l\left(2^{-1}\left(2^{n}+1\right)\right)+2^{r-1}\left(2^{n}+1\right)
\end{aligned}
$$

by the inductive hypothesis and Lemma 1 . The proof is completed by the use of Lemma 4.

3. Comments and questions. Since any positive integer can be written

$$
2^{c_{1}}+2^{c_{2}}+2^{c_{8}}+\cdots+2^{c_{n}}, \quad \text { where } \quad c_{1}>c_{2}>\cdots>c_{n} \geqq 0,
$$

one might expect to establish (3) by the ideas of this note (numbers for which $n=2$ having now been disposed of). However, the author has been unable to carry this through.

Other inequalities involving $l(p)$ would be of interest. One can easily show that $l(a+b) \leqq l(a)+l(b)$ if $a, b>1$. Does the inequality $l(p)<l(2 p)$ hold for all $p>0$ ? Let $S(n)$ denote the number of solutions of the equation $l(x)=n$. Is it true that $S(n)<S(n+1)$ for all $n>0$ ?

\section{BIBLIOGRAPHY}

1. A. T. Brauer, On addition chains, Bull. Amer. Math. Soc. vol. 45 (1939) pp. 736-739.

2. A. Scholz, Jber. Deutschen Math. Verein. vol. 47 (1937) p. 41.

UNIVERSITY OF MISSOURI 